\title{
ORGANIZACIJA ELEKTRONIČKOG POSLOVANJA S ASPEKTA MOBILNE NAPLATE
}

\author{
Milorad Ćupurdija, Karlo Kovač, Ljiljana Ćupurdija \\ VŠPU Baltazar Adam Krčelić - Zaprešić, Croatia
}

\begin{abstract}
:
Zbog rastućeg broja korisnika internetskog poslovanja i mobilnih tehnologija u smislu trgovanja elektroničkim sadržajem najpopularniji i najjednostavniji način mikro naplate je postao premium SMS i MMS servis (usluge sa dodanom vrijednosti). Sukladno navedenim trendovima osim tehničkih zahtjeva pojavio se i problem pravne regulative te zaštite krajnjih potrošača i pružatelja usluga.

Kako bi smo razjasnili navedene tvrdnje analizirat ćemo strukturu tehničke izvedbe internetskog poslovanja sa aspekta mobilne naplate i normativno pravne regulative elektroničkog poslovanja u Republici Hrvatskoj i Europskoj Uniji. Također, na praktičnom primjeru opisati tehničku izvedbu SMS premium servisa kao i moguće rizike s kojima se susreću krajnji korisnici i pružatelji usluga odnosno njihovu zaštitu s pravne strane.
\end{abstract}

\author{
Key words: \\ internetsko poslovanje, \\ elektronički sadržaj, \\ pružatelj usluge, \\ korisnik usluge.
}

\section{UVOD}

Ekspanzivnim razvojem komunikacijskih mreža i Interneta te velikim brojem njihovih korisnika rezultirali su time da se korisnici smatraju novim tržištem u kojem granice ne postoje. Također, kako su se tehnički razvijali mobilni uređaji njihovim korisnicima je omogućeno korištenje mobilnog interneta, a omogućavanjem toga, svaki vlasnik mobilnog uređaja postao je potencijalni kupac virtualnih ili fizičkih dobara. Ovim razvojem tehnologije tradicionalno poslovanje i trgovina postali su ravnopravni internetskom poslovanju i trgovini. Kako je Internet globalna mreža koja pruža neograničene mogućnosti, pojavila se neophodna potreba za pravnom regulacijom poslovanja u svrhu pravne regulative i zaštite pružatelja i korisnika usluga.

\section{Elektronička trgovina}

Elektronička trgovina (eng. Electronic commerce) definira se kao trgovina koja obuhvaća sve trgovačke transakcije, bilo da je riječ o onima između idividualnih, fizičkih osoba ili trgovačkih društava ili s njima izjedančenih subjekata, koja se provodi elektroničkim mrežama. Predmet takvih pravnih poslova mogu biti usluge i druge nematerijalne ili tjelesne stvari (eng. Intagible goods), podatci ili informacije, tzv. Data products, ili roba u tradicionalnom smislu kao tangible goods [1]. Dakle, elektronička trgovina je jedan od oblika trgovine, a pod pojmom elektroničke trgovine podrazumijeva se svaki oblik poslovanja između
Bit ovog načina poslovanja ogleda se u tome da poslovni subjekti međusobno trguju putem komunikacijskih mreža.

Prema statističkim podatcima Mediascopea ${ }^{1}$ vidljivo je kako je od rujna 2011. do veljače 2012. u Hrvatskoj potrošen 401 milijun eura na online kupnju, dok je u Europi taj iznos dosegao vrtoglavih 188 milijardi eura. S obzirom na to da se u Hrvatskoj u tom periodu Internetom koristilo oko $64 \%$ ljudi. Znakovito je da njih čak $98 \%$ traži mogućnost internetske kupovine, od kojih $80 \%$ i obavlja kupovinu putem intreneta, što je zapravo zanemarivo mali postotak u odnosu na europski prosjek koji iznosi $87 \%{ }^{2}$. Elektronička trgovina bilježi stalan rast. Prema Goldman Sachs ${ }^{3}$ multinacionalnoj investicijskoj tvrtki, predviđa se rast elektroničke trgovine na globalnoj razini od 19\% godišnje.

Elektronička trgovina je u 2013.-oj godini na globalnoj razini ostvarila promet od 936 biliona dolara, od čega je Europska Unija ostvarila 166.4 biliona dolara. U narednim godinama prediviđen rast elektroničke trgovine $\mathrm{u} \mathrm{EU}$ je u prosjeku $11 \%$, od čega se predviđa da će najveći rast ostvariti južne zemlje kao što su Italija i Španjolska. Također najveći potencijal za rast elektroničke trgovine ima istok Europske unije zbog same činjenice da je trenutno postotak udjela elektroničke trgovine vrlo nizak u odnosu

1 Mediascope - organizacija IAB Europe (Interactive Advertising Bureau)

2 Statistički podatci korišteni sa stranice: http://www.mingo.hr/ default.aspx?id=3306

3 Statistički podatci korišteni sa stranica: http://www.slideshare.net/ morellimarc/goldman-sachs-ecommerce-research-2013 http:// www.thinkwrap.com/globalecommercesales/ 
na zapadni dio EU (Rumunjska 7\% i Bugarska 6\% trenutnog udjela) ${ }^{4}$.

Zabilježen je trend rasta mobilne trgovine (eng. Mobile commerce) koja spada pod elektroničku trgovinu, a jedina razlika je da potrošači kupuju dobra preko mobilnih uređaja, a ne preko računala.

$S$ obzirm da se radi o starijim statističkim podatcima, smatra se da broj korisnika elektroničke trgovine odnosno internetske kupovine postaje sve veći i sukladno time postoji teza kako korisnici sve više postaju svjesni prednosti ovakvog način kupovine. Međutim isto tako razvidno je da postaje sve teže zaštiti sve subjekte u ovakvom načinu poslovanja koji ostavlja dovoljno prostora za različite malverzacije i različite oblike prijevara koje se mogu izbjeći klasičnom kupoprodajom.

\section{Prednosti elektroničke trgovine i vrste elektroničke trgovine}

Ovakav način trgovanja ima mnoge prednosti u odnosu na klasičnu trgovinu, kao što su niži troškovi poslovanja, globalna dostupnost 24/7/365, lakša interakcija i komunikacija između subjekata itd.

Između ostalog, potrebno je razlikovati i vrste elektroničke trgovine s obzirom na dobra kojima se trrguje, a razlikuje se „indirektna elektronička trgovina" ${ }^{5 “}$ koja obuhvaća nabavu fizičkih dobara te isporuku istih do krajnjeg kupca na tradicionalan način, te „direktna elektronička trgovina $^{6 “} \mathrm{tj}$. Trgovanje elektroničkim sadržajima poput softvera i drugih neimovinskih dobara isključivo u digitalnom obliku. Rad se bazira isključivo na direktnoj elektroničkoj trgovini - trgovanju elektroničkim sadržajem, a koji uključuje naplatu putem mobilnih tehnologija.

\section{Prepreke i izazovi elektroničke trgovine}

Jedna od glavnih prepreka i izazova u začecima elektroničke trgovine, pa čak i danas je strah kupaca da pri ovakvom načinu trgovanja može doći do različitih vrsta prijevara, povreda privatnosti, a jedan od osnovnih strahova je i krađa osobnih podataka. Kako se rad bazira na mobilnoj naplati i kako su iznosi naplaćenih sadržaja relativno mali, ovakav način trgovanja se počinje smatrati sve prihvatljivijim.

Dakako usprkos svemu navedenom u praksi nerijetko postoje različite žalbe kupaca vezane uz različite oblike navodnih prijavara, kao što je npr. da im nije isporučen naplaćeni sadržaj, isporuka pogrešnog sadržaja, naplata koja nije sukladna navedenim uvjetima prilikom kupnje i sl. Kako bi se to što bolje približilo, u radu je naveden primjer cjelokupne tehničke komunikacije između subjekata u ciklusu trgovanja čime će se nastojati približiti teza

4 Statistički podatci korišteni sa stranica:

https://ec.europa.eu/digital-agenda/sites/digital-agenda/files/ RO\%20internet\%20use_0.pdf

http://epp.eurostat.ec.europa.eu/statistics_explained/index.php/Ecommerce_statistics

5 Prema: http://www.pravnadatoteka.hr/pdf/NormativniOkvirZaElektronickoPoslovanjeURH.pdf

6 Prema: http://www.pravnadatoteka.hr/pdf/NormativniOkvirZaElektronickoPoslovanjeURH.pdf kako nerijetko svaka prijevara nije svjesno učinjena na štetu jednog od subjekata, nego su moguće nenamjerne pogreške uzrokovane ljudskom ili tehničkim čimenicima.

\section{PREMIUM7 SMS I MMS SERVISI}

Masovnim korištenjem SMS (eng. Short message service) i MMS (eng. Multimedia messaging service) tehničkim rješenjima stvorena je mogućnost naplate „potrošača [2]“ (u daljnjem tekstu - korisnik) i za iznose veće od klasične SMS ili MMS poruke odnosno tzv. „usluge s posebnom tarifom [3]“. Kreiranjem „kratkih kodova [4]“ od strane „operatora [5]“ stvara se mogućnost naplate premium poruka.

\section{Naplata premium poruka}

Naplata se može izvršiti na dva načina u odnosu na smjer iniciranja naplate: (1) MO (eng. Mobile originated) i (2) MT (eng. Mobile terminated).

MO način podrazumijeva da je naplata izvršena samim slanjem SMS ili MMS poruke prema određenom kratkom broju i inicirana je direktno od krajnjeg korisnika, dok MT naplata podrazumijeva da zahtjev za naplatu dolazi od strane „korisnika usluge [6]“.

U konačnici sami premium SMS i MMS servisi temelje se na integraciji sustava za naplatu operatora i određene aplikacije, igre ili web servisa.

Zbog ekonomskih razloga isplativosti direktne integracije web servisa ili aplikacije sa opratorom u komunikacijskom procesu se pojavljuje „davatelj usluge [7]“. Davatelj usluge već ima ugovore sa operatorom za određene kratke kodove ${ }^{8}$, a sve zahtjeve poslane sa njegovih IP adresa operatorov sustav prihvaća. Većim brojem korisnika preko istog kratkog koda same korisnike usluga čine konkurentnijima. U praksi davatelji usluga su tvrtke koje imaju ugovore sa operatorima (konekcije) u više zemalja te pružaju i usluge tehničke podrške te su odgovorne za informiranje krajnjih korisnika o naplati i dužni su poštovati pravila koja je regulator dao u određenoj zemlji.

\section{Objašnjenje osnovnih pojmova i način iniciranja naplate premium SMS ili MMS servisa}

Kako bismo što bolje razumjeli način iniciranja naplate premium usluga, potrebno je razlikovati subjekte koji sudjeluju u procesu trgovanja elektroničkim sadržajem, a koji su regulirani Zakonom o elektroničkoj trgovini. Prema navedenom Zakonu, DAVATELJEM USLUGA

7 Usluga s posebnom tarifom - $\mathrm{u}$ tekstu označavana kao premium poruka, odnosno premium SMS/MMS

8 kratki kodovi: su posebni kraći telefonski brojevi koji se koriste za glasovne i SMS/MMS usluge. Upotrebljavaju se za pristup hitnim službama, uslugama bez posebne tarife i uslugama s posebnom tarifom (npr. usluge od društvenog značaja, usluge davanja obavijesti o informacijama pretplatnika, posebnim uslugama od javnog interesa itd.) Duljina kratkih kodova iznosi od tri do šest znamenaka, a u posebnim okolnostima (kod nedostatnog kapaciteta) može imati i više znamenaka (Pravilnik o načinu i uvijetima obavljanja djelatnopsti elektroničkih komunikacijskih mreža i usluga NN 73/08 i 90/11) 
(podugovaratelj) se smatra „svaka pravna ili fizička osoba koja pruža usluge informacijskog društva“, odnosno KORISNIK USLUGE je svaka fizička ili pravna osoba koja zbog profesionalnih ili drugih ciljeva koristi uslugu informacijskog društva". KRAJNJI KORISNIK, odnosno POTROŠAČ je „svaka fizička osoba koja sklapa pravni posao na tržištu u svrhe koje nisu namijenjene njezinu zanimanju niti njezinoj poslovnoj aktivnosti ili poduzetničkoj djelatnosti, a u skladu s odredbama posebnog zakona“.

Shematski to možemo prikazati na sljedeći način:

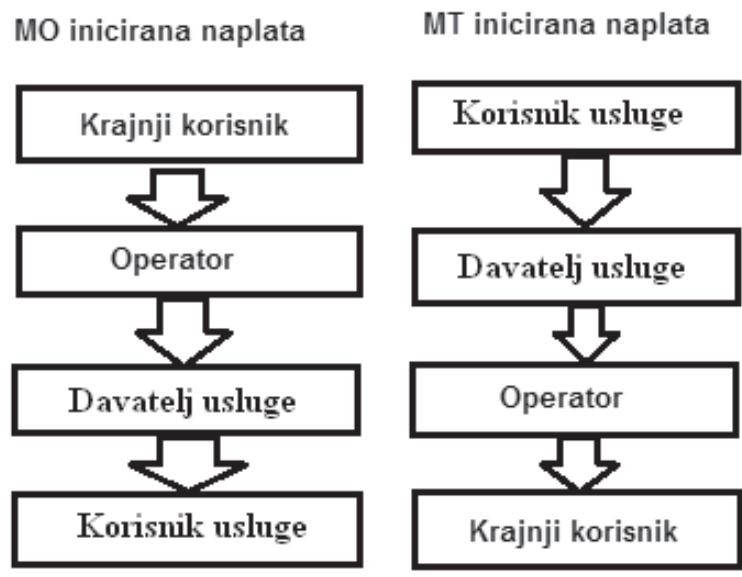

S1 .1. Načini iniciranja naplate premium sms ili mms servisa

$\mathrm{Na}$ slici 1. Su prikazani načini iniciranja naplate $\mathrm{MO}$ i MT.

MO način naplate se obično koristi za jednokratno plaćanje dobara, te ga inicira korisnik slanjem prije zadane ključne riječi na određeni kratki kod. Kada krajnji korisnik pošalje SMS na određeni kratki kod, operator odmah vrši naplatu i to ukoliko korisnik ima dovoljno sredstava na računu, a zatim proslijeđuje zahtjev prema korisniku usluge koji nakon primitka istog, isporučuje kupljeno dobro krajnjem korisniku. U praksi se jednokratno plaćanje koristi najčešće za SMS glasanja, chat servise itd. Najvažnija karakteristika ovog načina naplate je jednokratnost.

MT način naplate je iniciran od strane korisnika usluge slanjem zahtjeva sa parametrima cijene prema operatoru. Kada operator primi naplatni zahtjev on provjerava je li naplata moguća, odnosno ima li korisnik dovoljno sredstava na računu te vrši naplatu. Ukoliko korisnik nema dovoljno sredstava za naplatu ili postoji drugi problem koji onemogućuje naplatu, operator šalje prema korisniku usluge izvješće (eng. notification) je li naplata prošla uspješno ili nije, na temelju čega korisnik usluge omogućava kranjem korisniku korištenje iste. MT naplata se u praksi obično koristi za pretplatničke servise u kojima se naplata vrši periodički dok korisnik ne pošalje zahtjev za prekidom pretplate u obliku SMS poruke sa tekstom „STOP“.

\section{Komunikacijski protokoli i značaj davatelja usluge}

Najčešće korišteni komunikacijski protokol između korisnika usluga i davatelja usluga je HTTP protokol (engl. Hypertext transfer protocol). Razlog tome je što je HTTP glavni i najrašireniji komunikacijski protokol na web-u.
S druge strane najčešće korišteni protokol između operatora i davatelja usluge je SMPP protokol (eng. Short message peer to peer), što ne isključuje i ostale protokole pa i HTTP. SMPP protokol je prilagođen telekomunikacijskim sustavima za prijenos poruka i podataka između sustava samih telekoma, operatora.

Kako su komunikacijski protokoli korisnika usluge i operatora različiti, krucijalan značaj imaju davatelji usluga čiji gateway uređaji (prevodilac protkola) pretvaraju protokole te time omogućuju tok informacija od krajnjeg korisnika do korisnika usluga i obratno uz različite komunikacijske protokole.

Osim SMPP protokola, komunikacija na relaciji davatelj usluga - operator može biti i bilo kojim drugim protokolom koji definira operator u njegovoj tehničkoj dokumentaciji. Također, nerijetko se događa da operator inzistira na posebnom zahtjevu za naplatu, te posebno slanje teksta poruke. To znači da davatelji usluga moraju slati poseban zahtjev na operatorovu naplatnu platformu, a poseban za slanje teksta naplatne poruke. Obično svaki operator ima svoju naplatnu platformu, ali je u praksi moguće da dva ili više operatora koriste istu naplatnu platformu. Primjer za to je naplatna platforma MONETA koju koriste operatori u Republici Sloveniji, dok u Republici Hrvatskoj svaki operator koristi svoju naplatnu platformu i svaki ima svoje zahtjeve za način slanja i oblik naplatnog zahtjeva.

\section{Primjer toka naplate iniciranog od strane korisnika usluge - MT tok}

Naplatni zahtjev poslan od strane korisnika usluge:

07.03.2014 17:09:38:133 DEBUG <http-

213.197.182.48:21384>[HTTPClientAdapter]Received request:GET/premium?command=submitMessage๘us ername $=x x x x x \&$ password $=x x x x x \& m s i s d n=00385 x x x x$ $x x \& b u$ sinessNumber $=x x x x x \&$ price $=2500 \&$ sessionId $=8$ 8208HRA 1383844821014むcontent=Placanje\%20je\%20 izvrseno\%20uspjesno.\%20U\%20slucaju\%20poteskoca\%20 molimo\%20pisite\%20na\%20info HTTP/1.1

Nakon što sustav davatelja usluge primi zahtjev, on šalje odgovor prema sustavu korisnika usluge kao potvrdu da je zahtjev uspješno primljen. Bez ove potvrde sustav korisnika usluge ponavlja slanje zahtjeva.

Potvrda da je zahtjev uspješno primljen:

07.03.2014 17:09:38:160 DEBUG <http-

213.197.182.48:21384> [HTTPClientAdapter] Sending

data: $<$ res $>$

$<$ resultCode $>100</$ resultCode $>$

$<$ resultText $>\mathrm{OK}</$ resultText $>$

$<$ messageId $>91230876</$ messageId $>$

$<$ sessionId $>88208$ HRA1383844821014</sessionId $>$ $</$ res $>$

Nakon što je davatelj usluge uspješno poslao zahtjev za naplatu prema operatorovim sustavima i oni su uspješno izvršeni, te je kranji korisnik uspješno primio obavijest o naplati, davatelj usluge šalje notifikaciju (izviječće) o uspješnoj dostavi i naplati prema korisniku usluge, nakon čega krajnji korisnik dobiva kupljeno dobro. 
Izvješće poslano prema korisniku usluge:

07.03.2014 17:11:21:377 TRACE [HttpRequest-www. erodate.hr] Sending POST request to http://www.someurl.hr/nth.php:messageStatusText $=$ Message + sent.èt $i$ $m e=2014-03-07+17 \% 3 A 11 \% 3 A 21 \& b u$ siness Number $=x x$ $x x x$ rsessionId $=88208$ HRA 1383844821014 \& msis $d n=003$ $85 \times x \times x \times x \times x \&$ command $=$ deliverReportermessageId $=9123$ 0876\&messageStatus $=2$

Korisnik usluge potvrđuje primitak izvješća sa odgovorom:

07.03.2014 18:14:40:572 DEBUG [HttpRequest-195.29.118.66] Response code 200, OK

Naplatni zahtjev poslan prema operatoru ovisi o protokolu koji zahtjeva operator te o tehničkoj dokumentaciji operatora koja opisuje potrebne parametre u zahtjevu.

Oblik naplatnog zahtjeva definira sam operator u njegovoj tehničkoj dokumentaciji koja je specifična za svakog pojedinog operatora.

\section{NORMATIVNO - PRAVNA REGULATIVA}

Područje Elektroničke trgovine u RH regulirano je prvenstveno odredbama „Zakona o trgovini [8]“, te odredbama „Zakona o elektroničkoj trgovini [9]“"koji su u potpunosti usklađeni sa zakonodavstvom Europske unije u navedenom području. Također, primjenjuju se i mnoge druge odredbe među kojima su i „Zakon o zaštiti potrošača[10]“, odredbe „Zakona o trgovačkim društvima [11]“itd.

\section{Pravila i obveze vezane za premium usluge $u$ Republici Hrvatskoj}

U Republici Hrvatskoj pravila i obveze vezane za premium usluge je definirao HAKOM ${ }^{9}$ „Pravilnikom o načinu i uvijetima obavljanja djelatnosti elektroničkih komunikacijskih mreža i usluga [12]“. U navedenom Pravilniku postoji i posebno poglavlje „Usluge s posebnom tarifom“" gdje je definirano da je za poštivanje pravila o uslugama s dodanom vrijednosti odgovoran operator.

Ukoliko korisnik prijavi nepravilnosti agenciji HAKOM, Agencija obaviještava operatora koji je dužan dati očitovanje u roku od 5 radnih dana.

Ukoliko agencija smatra potrebnim, u skladu s okolnostima, ima pravo zatražiti od svih operatora da blokiraju pristup brojevima i servisima, te također da obustave prihod na navedenu uslugu.

Operator je dužan obavijestiti korisnika premium usluga ukoliko je potrošio više od 150 kuna, te ukoliko korisnik ne pošalje potvrdu da želi nastaviti koristiti servis, operator je dužan odjaviti korisnika.

Također, prilikom prve prijave korisnika na određeni servis prije nego krajnji korisnik primi naplatnu poruku, operator je obavezan poslati korisniku sms poruku, odnosno zahtjev da krajnji korisnik potvrdi da pristaje na prijavu na određeni servis i naplatu. Informacijska poruka mora sadržavati informacije o nazivu servisa, cijenu i frekvenciju naplate, te način odjave.

9 Hrvatska agencija za poštu i elektroničke komunikacije
Slanjem SMS-a sadržaja DA na određeni kratki broj krajnji korisnik potvrđuje prihvaćanje uvjeta koje je prije primio u informacijskoj prouci. Ukoliko korisnik ne pošalje potvrdan odgovor u vremenskom periodu od 120 min, operator mora smatrati da se korisnik ne slaže sa uvijetima iz informacijske poruke te usluga ne smije biti naplaćena. Također, bitno je napomenuti kako sve informacijske poruke poslane krajnjem korisniku moraju biti besplatne.

U praksi ukoliko dođe do primjedbi krajnjih korisnika oni prvo kontaktiraju operatora na besplatne info brojeve, nakon čega operator inzistira na provjeri. Krajnjim korisnicima se u večini slučajeva odobrava povrat novca mimo HAKOM-a. A također je i praksa ukoliko oštećeni korisnici kontaktiraju direktno korisnika usluge ili davatelja usluge da nakon provjere i analize slučaja odobrava se povrat.

Svaki pojedini servis ima dodjeljenu određenu ključnu riječ čijim slanjem u sms poruci krajnji korisnik inicira prijavu, a samim time i kasniju naplatu određene usluge ili dobra. Ključna riječ prema tome predstavlja skup znakova koje sustav prepoznaje i prema tome određuje kojem točno servisu korisnik želi pristupiti, u praksi operator najčešće ne dopušta da ključne riječi imaju manje od tri znaka.

\section{Tehnički preduvijet za aktivaciju premium usluga}

Tehnički preduvijet za aktivaciju premium usluga je aktivacija ključnih riječi od strane operatora. Proces aktivacije premium usluga se razllikuje ovisno o zemlji i operatoru.

U praksi zapadne zemlje EU imaju vrlo jednostavnu i kratku proceduru naručivanja određene ključne riječi, te se procedura naručivanja svodi na slanje elektroničke pošte operatorima sa kratkim opisom servisa ili usluge, nazivom ključne riječi, cijenom i frekvencijom naplate. Istočne zemlje u praksi imaju kompliciranu proceduru prijave novog servisa, ključne riječi koje obuhvaća popunjavanje raznih formulara te je osjetno povećana birokratizacija što ujedno i utječe na vrijeme potrebno za aktivaciju usluga.

\section{Provođenje regulative u praksi}

Iako je pravna regulativa SMS I MMS premium usluga vrlo dobro napisana i prihvaćena od strane regulatora svih zemalja ipak postoji značajna razlika u provedbi, kontroli i zaštiti na relaciji krajnji korisnik - pružatelj usluge po pojedinim zemljama EU.

Jedan od primjera je da je korištenje određenih usluga koje su zabranjene maloljetnicima u svim zemljama svijeta, odnosno osobama ispod 18 ili 21 godinu, ovisno o državi u kojoj se usluga pruža. Također u skladu s navedenim u svim zemljama je pravno regulirano da operator mora prije pristupanja takvom servisu tražiti potvrdu od krajnjeg korisnika da je osoba starija od godina koje su navedene $\mathrm{u}$ info poruci. Međutim, $\mathrm{u}$ praksi je to gotovo neizvedivo, jer se ne može znati tko stoji iza mobilnog uređaja i u takvim slučajevima zaštita maloljetnog korisnika je upitna. 
U praksi je ipak još uvijek mnogo slučajeva zloupotrebe i zaobilaženja pravne regulative kako od strane korisnika usluga, davatelja usluga, operatora pa i samih krajnjih korisnika pri čemu možemo zaključiti kako još uvijek nema načina potpuno zaštiti subjekte koji sudjeluju u procesu elektroničkog trgovanja i općenito poslovanja putem komunikacijskih tehnologija.

\section{ZAKLJUČAK}

Analizom normativno pravne regulative iz područja koje obuhvaća elektroničko poslovanje i njenom pratkičnom primjenom možemo izvuči sljedeće zaključke:

1. Određivanje pojmova nerjetko je nerazumljivo stručnjacima pravne i informatičke struke, što u praksi dovodi do zabune tko su subjekti ovakvog načina poslovanja. Npr. to se ogleda kroz nedorečenost pojma davatelja usluge, jer se u praski u biti radi o davatelju konekcije. U radu je to objašnjeno činjenicom da je cijena same konekcije vrlo visoka korisniku usluge i tehnički relativno zahtjevna.

2. Razlika u procesima aktivacije usluga i servisa je različita ovisno o zemlji i operatoru, a u praksi se to očituje u jednostavnosti i brzoj aktivaciji u zapadnim zemljama EU, te nepotrebnoj birokratizaciji istočnih zemalja EU. Takva razlika utječe na samo poslovanje informacijskih društava.

3. Iako postoji više prednosti poslovanja putem komunikacijskih mreža i ono bilježi stalni rast i dalje ostaje najveći nedostatak zaštita svih subjekata ovog načina poslovanja.

\section{ZAHVALNICA}

Želimo se zahvaliti Visokoj školi za poslovanje i upravljanje Baltazar Adam Krčelić na pomoći i financiranju u izradi ovog rada.

\section{LITERATURA}

[1] Tin Matić: "Pravo virtualnih pravnih odnosa: Elektronička trgovina, NN, Zagreb 2012 (str. 9)”

[2] Zakon o elektroničkim komunikacijama, pročišćeni tekst zakona (NN br. 73/08, 90/11, 133/12, 80/13)

[3] Zakon o elektroničkim komunikacijama, pročišćeni tekst zakona (NN br. 73/08, 90/11, 133/12, 80/13)

[4] Pravilnik o načinu i uvjetima obavljanja djelatnosti elektroničkih komunikacijskih mreža i usluga, HAKOM (NN br. 73/2008. I 90/2011.)

[5] Zakon o elektroničkim komunikacijama, pročišćeni tekst zakona (NN 73/08, 90/11, 133/12, 80/13)

[6] Zakon o elektroničkim komunikacijama, pročišćeni tekst zakona (NN br. 73/08, 90/11, 133/12, 80/13)

[7] Zakon o elektroničkim komunikacijama, pročišćeni tekst zakona (NN br. 73/08, 90/11, 133/12, 80/13)

[8] Zakon o trgovini (NN 87/08, 96/08, 116/08, 76/09, 114/11)

[9] Zakon o elektroničkoj trgovini (NN 173/03, 67/08, 36/09 i 130/11)

[10] Zakon o zaštiti potrošača (NN 79/07, 125/07, 79/09, 89/09, 133/09, 78/12)

[11] Zakon o trgovačkim društvima (NN 111/93, 34/99, 52/00, $118 / 03,107 / 07,146 / 08,137 / 09,125 / 11,152 / 11,111 / 12$ i 68/13)

[12] Pravilnik o načinu I uvjetima obavljanja djelatnosti elektroničkih komunikacijskih mreža I usluga (NN 73/08 i 90/2011)

\section{ORGANIZATION OF E-BUSINESS IN TERMS OF MOBILE BILLING}

\begin{abstract}
:
Because of increasing number of Internet business and mobile technology users regarding to trade of electronic content, most popular and most easiest way of micro-billing are premium sms and mms services. According to the given trends except technical requirements, appeared legislative regulation issue in order to protect end users and service providers. In order to clarify given assertions in this paper is analyzed technical structure of Internet business from the point of mobile biling and normative legal regulation of e-business in Republic of Croatia and European Union. Also, on practical example is described technical design of sms premium services and possible risk of end users and service providers, respectively their protection from the legal point of view.
\end{abstract}

\section{Key words:}

Internet business, electronic content, service provider, service users. 